\title{
Book Review: Education and Climate Change: The Role of Universities
}

\author{
Philip Bell ${ }^{*}$ and Arcadia Payne* \\ Harvard Graduate School of Education, Cambridge, MA, United States
}

Keywords: climate education, universities and higher education institutions, education, partnerships, contextual education

\author{
A Book Review on \\ Education and Climate Change: The Role of Universities \\ Fernando M. Reimers (New York, NY: Springer), 2021, XIII, 201 pages, ISBN: 978-3-030-57927-2
}

Reimers's new edited book, Education and Climate Change, reimagines the role of higher education institutions as avenues through which to drive contextual climate change education (CCE). Fernando Reimers and various contributors write chapters about their experiences and efforts to expand the capacity for education systems to address climate change and equip students worldwide with the skills, knowledge, and ethical frameworks to tackle localized climate challenges. The authors of this review are both former students of Dr. Reimers at the Harvard Graduate School of Education.

The volume contains a collection of climate education case studies delivered by graduate students. Reimers and his co-authors analyze the settings of Israel, Guatemala, Haiti, Pakistan, and the United States to position universities as innovative partners in the quest for relevant, rigorous CCE. They argue university partnerships can spur localized educational content specific to regional needs and that the inherently contextual nature of climate impacts necessitate a granular approach to climate education.

The chapters vary in the extent to which they elaborate on the role of universities in contextual CCE. In chapter two Rhodes and Wang describe coordination with the Arava Institute in Southern Israel to create a curriculum to "enable students to conceptualize and help address climate change problems in the region" in the setting of secondary formal schooling institutions (p. 45). Chapter six, by Nam and Lee, outlines the process of building CCE curriculum at the graduate school level, elevating the concept that a multilateral approach (in this case, one that centers graduate students within tertiary schools of education) facilitates innovative design efforts in this field. Due to the variable nature of the roles universities can play in CCE in each chapter, it is unclear how the authors recommend universities get involved in developing and disseminating CCE. The assorted chapters are not a collection of "best practices" for how tertiary institutions can play a role in progressing the field of CCE, but rather a selection of case studies outlining various forms of involvement that universities can choose to pursue based on community needs.

The common use of Reimers's five perspectives (cultural, psychological, professional, institutional, and political) works well throughout the book, urging a multifaceted and systemslevel view of the challenges and opportunities facing the design and implementation of climate change education in various contexts. In a rapidly changing world where adaptation is necessary, Reimers is wise to refrain from suggesting a "silver bullet," instead offering a framework for locales to construct more authentic and reasonable climate change education reforms. Even within countries, challenges and opportunities vary across regions or cities, as shown in chapter two and chapter three, so it is critical to leverage high-capacity institutions, such as universities and colleges, 
to craft localized CCE curricula.

The insights from the book might be operationalized more powerfully through comparison to existing literature. For example, the particular salience of action-oriented learning in this field has been identified by (Stevenson, 2007, p. 146), who argues that the necessary knowledge and skills emerge in the context of taking action, while Uzzell, 1999, p. 398) has highlighted how self-efficacy in the context of CCE distributed within a community drives meaning-making.

Perhaps most importantly, this volume is concerned with the mechanics of building capacity to deal with the complex problems thrown up by climate breakdown. (Scott and Vare, 2007, p. 192) proposal of three levels of ESD (Education for Sustainable Development) has been seminal in theorizing the importance of critical reasoning as a component of ESD. The first level involves building the short-term skills and behaviors needed to deal with known and fixed problems, the second with critical reasoning that allows learners to question paradigmatic assumptions. The third, which is rare to see in practice, involves building the capacity to deal with radical uncertainty and imprecise problems. This widely used model might be used as

\section{REFERENCES}

Scott, W., and Vare, P. (2007). Learning for a change: exploring the relationship between education and sustainable development. J. Educ. Sustain. Dev. 1, 191-198. doi: 10.1177/097340820700100209

Stevenson, R. (2007). Schooling and environmental education: contradictions in purpose and practice. Environ. Educ. Res. 13, 139-153. doi: $10.1080 / 13504620701295726$

Uzzell, D. (1999). Education for environmental action in the community: new roles and relationships. Cambridge J. Educ. 29, 397-413. a framework to categorize and analyse the CCE interventions in this book, and to signpost where each case study sits on the spectrum from instrumentalist skill development to deep capacity-building. Ultimately, this model might serve as a platform to confront the trade-offs inherent in any scheme of CCE. For example, should deep critical engagement be prioritized over interdisciplinarity (as Scott argues) if it is not possible to achieve both?

Taken together, the chapters in this book represent a powerful argument for a symbiosis between universities working with educational organizations to create climate curricula that are context-specific. More than anything, this book shows that from Sindh to Port au Prince to the Western Highlands of Guatemala, universities can be an effective partner in realizing effective climate education.

\section{AUTHOR CONTRIBUTIONS}

We appreciate the opportunity to work as co-authors on this book review. Both authors contributed to the article and approved the submitted version.

Conflict of Interest: PB and AP are former students of Dr. Reimers at the Harvard Graduate School of Education.

Copyright (C) 2021 Bell and Payne. This is an open-access article distributed under the terms of the Creative Commons Attribution License (CC BY). The use, distribution or reproduction in other forums is permitted, provided the original author(s) and the copyright owner(s) are credited and that the original publication in this journal is cited, in accordance with accepted academic practice. No use, distribution or reproduction is permitted which does not comply with these terms. 